\title{
Quantificação do enrijecimento muscular de peito de frango causado por formaldeído
}

\author{
Bruno Henrique Lopes Guastalli ${ }^{1}$ \\ Teresa Chorense Nunes ${ }^{1}$ \\ Thaís Helena Martins Gamón ${ }^{1}$ \\ Lígia Grisólia do Carmo ${ }^{1}$ \\ Erci Marcos Del Quiqui \\ Fabrício Singaretti de Oliveira ${ }^{1 *}$
}

\author{
${ }^{1}$ Depto de Medicina Veterinária \\ ${ }^{2}$ Depto de Ciências Agronômicas \\ Universidade Estadual de Maringá, Campus Umuarama \\ Caixa Postal 65, CEP 87501-970, Umuarama - PR, Brasil \\ *Autor para correspondência \\ singaretti@ig.com.br
}

Submetido em 03/03/2011

Aceito para publicação em 30/09/2011

\section{Resumo}

A maciez ou textura do peito de frango pode ser avaliada pela mensuração da força necessária para ocorrer o cisalhamento das fibras musculares. O objetivo deste trabalho foi quantificar o enrijecimento muscular em peitos de frango submetidos à fixação e conservação em formaldeído a 10\%, ao longo de um ano. As análises foram feitas em peitos frescos (grupo controle) e em amostras com 7, 15, 30, 90, 180 e 360 dias de conservação. A força de cisalhamento variou de 3,38 kgf (grupo controle) a 17,37 kgf (grupo de 30 dias). No grupo de 15 dias de conservação, houve uma pequena queda nessa força (14,74 kgf), quando comparado aos grupos de 90 (16,94 kgf), 180 (16,71 kgf) ou 360 dias (15,42 kgf). Conclui-se que, quando peitos de frango são submetidos à fixação e conservação em solução aquosa de formaldeído $10 \%$, ocorre diminuição da maciez, tornando-os quase cinco vezes mais rígidos ao cisalhamento a partir de sete dias de conservação nessa solução.

Palavras-chave: Força de cisalhamento, Formaldeído, Textura

\section{Abstract}

Quantification of chicken breast muscle stiffening caused by formaldehyde. Tenderness or texture of chicken breast may be evaluated through measuring the force needed to lead to the rupture of muscle fibers. The aim of this paper was to quantify the muscle stiffening in chicken breasts which underwent fixing and storage in $10 \%$ formaldehyde solution, throughout a year. The analyses were carried out in fresh chicken breasts (control group) and in samples at 7, 15, 30, 90, 180, and 360 days of conservation. The shear force varied from $3.38 \mathrm{kgf}$ (control group) to $17.37 \mathrm{kgf}$ (30-day group). In the 15-day conservation group there was a little force decrease (14.74 kgf), when compared to the 90 (16.94 kgf), 180 (16.71 kgf), or 360 (15.42 kgf) day groups. One concludes that, when chicken breasts underwent fixing and storage in $10 \%$ formaldehyde aqueous solution, tenderness is decreased, and they become almost five times harder after seven days of storage in this solution.

Key words: Formaldehyde, Shear force, Texture 


\section{Introdução}

A maciez, ou textura, de um músculo pode ser avaliada mediante um analisador conhecido como texturômetro (CULIOLI, 1995). Este aparelho mensura a força necessária para que uma lâmina rompa as fibras musculares de um fragmento tissular (força de cisalhamento - FC) e o resultado pode ser expresso em quilograma-força (kgf) (BOURNE, 1982; SOUZA, 2008), e em Newton (N), dentre outras unidades.

A maciez constitui um dos principais atributos sensoriais que determina a aceitabilidade global da carne de frango, enquanto a coloração do peito está associada à aceitabilidade no momento da aquisição do produto (BRESSAN; BERAQUET, 2002). Para a conservação de peças anatômicas, são utilizadas substâncias que impedem a proliferação de microorganismos. As mais comuns são o formaldeído, a glicerina, o álcool etílico e o fenol. O formaldeído é o fixador e conservante mais utilizado, comumente em solução aquosa a $10 \%$. Por ser barato e penetrar rapidamente nos tecidos (seis milímetros em doze horas) é amplamente utilizado nos laboratórios de anatomia (RODRIGUES, 1998).

Já foi descrita a quantificação do enrijecimento muscular peitoral de frangos causado pela conservação em solução aquosa de formaldeído a 3,8\% por 45 dias, observando-se que a média da FC do grupo controle (músculos frescos, sem fixação) foi sete vezes maior que a média da força necessária para o cisalhamento das fibras musculares do grupo do conservante (GUASTALLI et al., 2007). Contudo, diferentes tempos de conservação destas peças em solução aquosa de formaldeído a $10 \%$ não foram estudados.

Neste trabalho, tem-se como objetivo quantificar o enrijecimento de músculos peitorais de aves submetidos à fixação nos diferentes tempos de conservação ( 7 , $15,30,90,180$ e 360 dias) em solução aquosa de formaldeído a $10 \%$, visando mensurar as alterações quanto à firmeza muscular. Foram escolhidos os peitos de frango para este tipo de análise, pois estes músculos são muito homogêneos, e isolados facilmente de qualquer fáscia ou aponeurose que possa interferir nos resultados.

\section{Material e Métodos}

Frangos machos da linhagem Cobb, submetidos a uma mesma dieta, foram abatidos aos 42 dias de idade. Imediatamente após o abate, coletaram-se 56 músculos peitorais, sem osso, que foram pesados em balança digital de precisão $(445 \pm 27 \mathrm{~g})$ e, dos quais, 48 foram fixados mediante injeção por agulha $19 \mathrm{G}$ com solução aquosa de formaldeído $10 \%$, em volume correspondente a $10 \%$ do peso do músculo $(44,5 \pm 2,7 \mathrm{~mL})$. A seguir, o material foi conservado em recipientes de polietileno e mantidos na mesma solução em temperatura ambiente. As análises da FC foram feitas aos 7, 15, 30, 90, 180 e 360 dias de conservação, utilizando-se oito peitos em cada tempo, constituindo-se seis grupos de avaliação. Nos oito peitos restantes, a FC foi mensurada sem fixação ou conservação pelo formaldeído, ou seja, as peças foram avaliadas in natura (grupo controle), para comparação com os demais grupos.

Foram retiradas quatro amostras de cada músculo peitoral maior ( $M$. pectoralis major) na forma de paralelepípedo, com aproximadamente $2 \mathrm{~cm}$ de comprimento, largura e altura, as quais foram colocadas com as fibras orientadas no sentido perpendicular à lâmina do texturômetro (FRONING et al., 1978) (Warner-Bratzler TAZT2i ${ }^{\circledR}$ ), pertencente ao Laboratório de Alimentos do Departamento de Medicina Veterinária da UEM - Campus Umuarama, PR. Durante 24 horas seguidas antes das análises, as amostras foram lavadas em água corrente para se retirar o excesso do agente conservante.

Os dados foram submetidos à análise de variância e as médias comparadas pelo teste de Tukey $(\mathrm{P}<0,05)$ por meio do aplicativo Statgraphics ${ }^{\circledR}$.

\section{Resultados e Discussão}

A média da FC obtida na musculatura peitoral do grupo controle foi de (3,38 kgf) (Tabela 1), valor maior que aqueles reportados por Denadai et al. (2002) (2,25 a $3,17 \mathrm{kgf}$ ), Guastalli et al. (2007) (2,04 kgf) e Faria et al. (2008) (2,63 kgf) e menor do que o descrito por Contreras (1995) (5,5 a 5,8 kgf). A média da FC neste grupo foi similar à média de 2,92 a 3,50 kgf descrita por Bressan 
e Beraquet (2004) em peitos de frangos submetidos ao tratamento de pré-resfriamento e resfriamento.

TABELA 1: Força de cisalhamento (FC), em kgf, dos cortes de peito de frango fixados e conservados em solução aquosa de formaldeído a $10 \%$ em diferentes períodos. *Coeficiente de variação.

\begin{tabular}{c|c}
\hline Dias & FC \\
\hline $\mathbf{0}$ & $3,38^{\mathrm{a}}$ \\
$\mathbf{7}$ & $15,20^{\mathrm{b}}$ \\
$\mathbf{1 5}$ & $14,74^{\mathrm{b}}$ \\
$\mathbf{3 0}$ & $17,37^{\mathrm{d}}$ \\
$\mathbf{9 0}$ & $16,94^{\mathrm{d}}$ \\
$\mathbf{1 8 0}$ & $16,71^{\mathrm{cd}}$ \\
$\mathbf{3 6 0}$ & $15,42^{\mathrm{bc}}$ \\
$\mathbf{C V} \boldsymbol{( \% )}$ & 35,55 \\
\hline
\end{tabular}

Médias com letras distintas diferem entre si pelo teste de Tukey $(\mathrm{P}<0,05)$.

Todos os grupos diferiram estatisticamente do grupo controle $(\mathrm{P}<0,05)$ e não houve diferenças significativas entre os grupos de sete e 15 dias, os quais foram similares ao grupo de 360 dias. Ainda, os grupos de 30 e 90 dias também não diferiram entre si e foram similares ao grupo de 180 dias.

AFC dos peitos de frango mantidos em formaldeído aumentou de maneira rápida e aos sete dias já apresentava valor de 15,20kgf. Os valores nos demais períodos de conservação mantiveram-se altos, e variaram de 14,74 a 17,37kgf. O comportamento destes resultados foi similar aquele descrito por Guastalli et al. (2007), cuja média foi de $15,32 \mathrm{kgf}$ para peitos de frango conservados por 45 dias em formaldeído a 3,8\%.

Conclui-se que o músculo peitoral de frangos, quando submetidos à fixação e conservação em solução aquosa de formaldeído $10 \%$, torna-se entre 4,4 e 5,0 vezes mais rígido que aquele fresco nãofixado, e esta rigidez ocorre logo com uma semana de conservação e se mantém ao longo dos demais períodos analisados.

\section{Referências}

BOURNE, M. C. Principles of objective texture measurement. In: BOURNE, M. C. (Ed.). Food texture and viscosity: concept and measurement. New York: Academic Press, 1982. p. 114-117.

BRESSAN, M. C.; BERAQUET, N. J. Efeito de fatores préabate sobre a qualidade da carne de peito de frango. Ciência e Agrotecnologia, Lavras. v. 26, n. 5, p. 1049-1059, 2002.

BRESSAN, M. C.; BERAQUET, N. J. Tratamentos de préresfriamento e resfriamento sobre a qualidade de carne de peito de frango. Ciência e Tecnologia de Alimentos, Campinas, v. 24, n. 2, p. 230-235, 2004.

CONTRERAS, C. J. C. Efeitos do atordoamento elétrico, estimulação elétrica e da desossa quente na qualidade da carne do peito de frango (Pectoralis major). 1995. 150 f. Dissertação (Mestrado em Tecnologia de Alimentos) - Universidade Estadual de Campinas, Campinas. 1995.

CULIOLI, J. Meat tenderness: mechanical assessment. In: OUALI, A.; DEMEYER, D. I.; SMULDERS, F. J. M. (Ed.). Expression of tissue proteinases and regulation of protein degradation as related to meat quality. The Netherlands: Ecceamst, 1995. p. 239263.

DENADAI, J. C.; DENADAI, J. C.; ALMEIDA, I. C. L.; MOREIRA, J.; TAKITA, T. S.; PAVAN, A. C.; GARCIA, E. A. Efeito da duração do período de jejum pré-abate rendimento de carcaça e a qualidade da carne do peito de frango de corte. Revista Brasileira de Ciência Avícola, Campinas, v. 4, n. 2, p.101-109, 2002.

FARIA, P. B.; VICENTE NETO, J.; BRESSAN, M. C.; MESQUITA, F. V.; TAVARES, S. A.; GAMA, L. T. Qualidade da carne de marreco pequim branco (Anas platyrhynchos, L.1758) comparado a frango de corte. Ciência e Agrotecnologia, Lavras, v. 32, n. 1, p. 213-218, 2008.

FRONING, G. W.; BABJI, A. S.; MATHER, F. B. The effect of preslauther temperature, stress, strugle and anesthetization on color and textural characteristics of turkey muscle. Poultry Science, Savoy, v. 57, n. 3, p. 839-845, 1978.

GUASTALLI, B. H. L.; NUNES, T. C.; GAMON, T. H. M.; SADDI, L. G. C.; ZANI, F. L.; ÁVILA, M. A.; OLIVEIRA, F. S. Mensuração da textura de tecido muscular fixado e conservado em solução aquosa de formaldeído por 45 dias. In: CONGRESSO BRASILEIRO DE MEDICINA VETERINÁRIA, 34, 2007, Santos. Resumos... Santos: Sociedade Paulista de Medicina Veterinária, 2007. Disponível em <http://www.spmv.org.br/conbravet2007/ dados/web-trabalhos-anatomia.htm>. Acesso em: 20 Julho 2010.

RODRIGUES, H. Técnicas anatômicas. Vitória: Arte Visual, 1998. 222 p.

SOUZA, P. S. Comparação dos efeitos da temperatura de cocção e espessura da lâmina de corte na força máxima de cisalhamento Warner Bratzler, no Longissimus dorsi e, determinação de um modelo matemático que correlacione estes parâmetros com a força máxima de cisalhamento. PUBVET, Londrina, v. 2, n. 7, sem paginação, 2008.

STATISTICAL GRAPHICS CORPORATION. STATIGRAPHICS plus for Windows 4.1. 1994-1999. CD. 